\title{
Structural elucidation and antimicrobial characterization of novel diterpenoids from Fabiana densa var. ramulosa
}

Deborah Quaglio $^{\dagger}$, Silvia Corradi ${ }^{\dagger, \#}$, Silvia Erazo ${ }^{ \pm}$, Valeria Vergine $^{\dagger}$, Simone Berardozzi $^{\ddagger}$ Fabio Sciubba ${ }^{\ddagger}$, Floriana Cappiello ${ }^{\S}$, Maria Elisa Crestoni ${ }^{\dagger}$, Fiorentina Ascenzioni^, Francesco Imperi', Franco Delle Monache ${ }^{+}$, Mattia Mori', Maria Rosa Loffredo $^{\S}$, Francesca Ghirga ${ }^{\# *}$, Bruno Casciaro ${ }^{\# *}$, Bruno Botta $^{\dagger}$ and Maria Luisa Mangoni ${ }^{\S}$

†Department of Chemistry and Technology of Drugs, "Department of Excellence 2018-2022", Sapienza University of Rome, P.le Aldo Moro 5, 00185 Rome, Italy

\#Center For Life Nano Science@Sapienza, Istituto Italiano di Tecnologia, Viale Regina Elena, 291, 00161 Rome, Italy

${ }^{ \pm}$Department of Pharmacological and Toxicological Chemistry, Faculty of Chemical and Pharmaceutical Sciences, University of Chile, Santiago, Chile;

‡Department of Chemistry and Applied Biosciences, ETH Zürich, Rämistrasse 101, 8092 Zürich, Switzerland

¥Department of Chemistry, Sapienza University of Rome, P.le Aldo Moro 5, 00185 Rome, Italy

${ }^{\S}$ Laboratory affiliated to Pasteur Italia-Fondazione Cenci Bolognetti, Department of Biochemical Sciences, Sapienza University of Rome, P.le Aldo Moro 5, Rome 00185, Italy;

${ }^{\wedge}$ Department of Biology and Biotechnology Charles Darwin, Sapienza University of Rome, Laboratory affiliated to Pasteur Italia-Fondazione Cenci Bolognetti, Rome, Italy

'Department of Sciences, Roma Tre University, Rome, Italy

${ }^{+}$Centro Chimica dei Recettori, C.N.R., Roma, Italy

'Department of Biotechnology, Chemistry and Pharmacy, "Department of Excellence 2018-2022”, University of Siena, via Aldo Moro 2, 53100 Siena, Italy 


\section{Table of contents}

\section{Chemistry experimental section}

1.1 General methods and instrumentation

1.2 Procedures and compounds characterization

1.2.1 Extraction and isolation of compounds 1-9

1.2.2 Characterization of compounds $\mathbf{1 - 9}$

1.2.3 ${ }^{1} \mathrm{H}$ and ${ }^{13} \mathrm{C}$ NMR spectra of compounds $\mathbf{1 - 9}$

1.2.4 General procedure to synthesize compounds 2, 3, 4 from $\mathbf{1}$

\section{Biological assays}

2.1 Bacterial strains and cell line

2.2 Antimicrobial activity

2.3 Cytotoxicity assay

2.4. Statistical analysis

\section{References}




\section{Chemistry experimental section}

\subsection{General methods and instrumentation}

All non-aqueous reactions were performed under an argon atmosphere using flame-dried glassware and standard syringe/septa techniques.

All absolute solvents were purchased as anhydrous grade from Sigma Aldrich and used without further purification unless otherwise stated. Solvents for extractions, flash column chromatography (FC) and thin layer chromatography (TLC) were purchased as commercial grade from Sigma Aldrich and used without further purification unless otherwise stated. Reactions were magnetically stirred and monitored by TLC performed on Merck TLC aluminum sheets (silica gel 60 F254). Spots were visualized with UV light $(\lambda=254 \mathrm{~nm})$. Chromatographic purification of products (FC) was performed using Sigma Aldrich silica gel 60 for preparative column chromatography (particle size 40-63 $\mu \mathrm{m}$ ).

Melting points $(\mathbf{M p})$ were obtained in open capillary tubes usinga Büchi melting point apparatus B-545 and are uncorrected.

${ }^{1} \mathrm{H}$ NMR and ${ }^{13} \mathrm{CNMR}$ spectra were recorded in $\mathrm{CDCl}_{3}$, acetone$d_{6}$, DMSO- $d_{6}$ or methanol- $d_{4}$ on a Bruker AV-400 $400 \mathrm{MHz}$ spectrometer (operating at $400 \mathrm{MHz}$ for ${ }^{1} \mathrm{H}$ and $100 \mathrm{MHz}$ for ${ }^{13} \mathrm{C}$ ) at room temperature and tetramethylsilane (TMS) as internal standard. Chemical shifts $(\bar{\delta})$ are 
reported in parts per million (ppm) and are referenced to $\mathrm{CDCl}_{3}(\delta=7.26$ ppm for ${ }^{1} \mathrm{H}, \delta=77.16$ ppm for $\left.{ }^{13} \mathrm{C}\right)$, acetone- $d_{6}\left(\delta=2.05 \mathrm{ppm}\right.$ for ${ }^{1} \mathrm{H}, \delta=$ 29.84 ppm for $\left.{ }^{13} \mathrm{C}\right)$ DMSO- $d_{6}\left(\delta=2.50 \mathrm{ppm}\right.$ for ${ }^{1} \mathrm{H}, \delta 39.52 \mathrm{ppm}$ for $\left.{ }^{13} \mathrm{C}\right)$, or $\mathrm{MeOH}-d_{4}\left(\delta=3.31 \mathrm{ppm}\right.$ for ${ }^{1} \mathrm{H}, \delta 49.00 \mathrm{ppm}$ for $\left.{ }^{13} \mathrm{C}\right)$. All ${ }^{13} \mathrm{C}-\mathrm{NMR}$ spectra were measured with complete proton decoupling. Data for NMR spectra are reported as follows: $\mathrm{s}=$ singlet, $\mathrm{d}=$ doublet, $\mathrm{t}=$ triplet, $\mathrm{q}=$ quartet, $\mathrm{m}=$ multiplet, $\mathrm{br}=$ broad signal, $J=$ coupling constant in $\mathrm{Hz}$.

High-resolution mass spectra (HRMS) were recorded on Bruker BioApex Fourier transform ion cyclotron resonance (FT-ICR) mass spectrometer.

Mass spectra (HRMS) were recorded on BRUKER Esquire 3000 PLUS (Esi lon Trap LC/MSn System)

Plant material Aerial parts of Fabiana densa var. ramulosa were collected and identified by the School of Chemistry and Pharmacy, University of Chile.

\subsection{Procedures and characterization}

\subsubsection{Extraction and isolation of compounds 1-9}

The dried leaves of Fabiana densa var. Ramulosa $(600 \mathrm{~g})$ were extracted at room temperature with acetone for $24 \mathrm{~h}$ and filtered several times. The filtrate $(100 \mathrm{~g})$ was subjected to gravity column 
chromatography on silica gel and eluted with dichloromethane to give the diterpenic compounds: 5 (0.45\%), 6 (0.48\%), 7 (0.25\%), 1 (ent-beyer-15en-18-ol) (10\%) and a fraction (15 g) made by a mixture of five compounds. This fraction was subjected to a flash column chromatography on silica gel with a gradient mobile phase of $\mathrm{CHCl}_{3} / \mathrm{MeOH}$ obtaining five compounds: 8 (2\%), 9 (1\%) and 4 (ent-beyer15-en-18-O-succinate) (20\%) were obtained by elution with $\mathrm{CHCl}_{3} / \mathrm{MeOH}$ (98: 2); 3 (ent-beyer-15-en-18-O-malonate) (10\%) was obtained by elution with $\mathrm{CHCl}_{3} / \mathrm{MeOH}$ (97: 3); 2 (ent-beyer-15-en-18-O-oxalate) (5\%) was obtained by elution with $\mathrm{CHCl}_{3} / \mathrm{MeOH} /$ formic acid (97: 3: 1).

\subsubsection{Characterization of compounds 1-9}

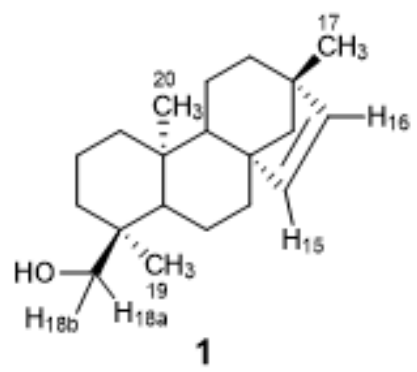

1. ent-beyer-15-en-18-ol. White powder (yield 10\%); m.p. $110{ }^{\circ} \mathrm{C} \pm 0.5$ ${ }^{\circ} \mathrm{C} ;[\alpha]_{\mathrm{D}}+29.7^{\circ}\left(\mathrm{CHCl}_{3}\right) ;{ }^{1} \mathrm{H}$ NMR $\left(400 \mathrm{MHz}, \mathrm{CDCl}_{3},\right) \delta 5.69(\mathrm{~d}, 1 \mathrm{H}, \mathrm{J}=5.7$ $\mathrm{Hz}, \mathrm{H}-15), 5.45$ (d, 1H, J=5.6 Hz, H-16), 3.41 (d, 1H, J=10.8 Hz, H-18a), $3.11(\mathrm{~d}, 1 \mathrm{H}, \mathrm{J}=10.8 \mathrm{~Hz}, \mathrm{H}-18 \mathrm{~b}), 0.99$ (s, 3H, $\left.\mathrm{CH}_{3}-17\right), 0.79$ (s, 3H, $\mathrm{CH}_{3-}$ 19), 0.77 (s, 3H, $\left.\mathrm{CH}_{3}-20\right) ;{ }^{13} \mathrm{C}$ NMR $\left(100 \mathrm{MHz}, \mathrm{CDCl}_{3}\right) \delta 136.55,135.34$, $72.44,61.31,52.91,49.16,49.11,43.77,38.87,37.70,37.25,37.12$, 
35.50, 33.31, 25.08, 20.35, 19.99, 18.08, 17.92, 15.72; ESI-MS (positive) $\mathrm{m} / \mathrm{z}$ : calcd. for $\mathrm{C}_{20} \mathrm{H}_{32} \mathrm{ONa} 311.2$, found $311.3[\mathrm{M}+\mathrm{Na}]^{+}$.

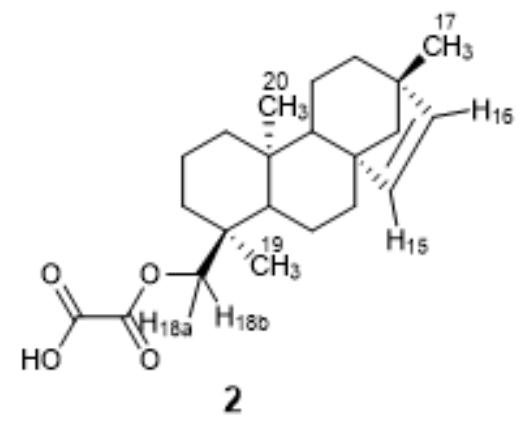

2. ent-beyer-15-en-18-0-oxalate. White powder (yield 5\%); m.p. 169.5 ${ }^{\circ} \mathrm{C} \pm 0.5 \stackrel{\circ}{\circ} \mathrm{C} ;[\alpha]_{\mathrm{D}}+10^{\circ}\left(\mathrm{CHCl}_{3}\right) ;{ }^{1} \mathrm{H}$ NMR $\left(400 \mathrm{MHz}, \mathrm{CDCl}_{3}\right) \delta 5.67(\mathrm{~d}, 1 \mathrm{H}$, $\mathrm{J}=5.7 \mathrm{~Hz}, \mathrm{H}-15$,), $5.46(\mathrm{~d}, 1 \mathrm{H}, \mathrm{J}=5.7 \mathrm{~Hz}, \mathrm{H}-16$,), $4.10(\mathrm{~d}, 1 \mathrm{H}, \mathrm{J}=10.8 \mathrm{~Hz}$, $\mathrm{H}-18 \mathrm{a}), 3.90$ (d, 1H, J=10.8 Hz, H-18b), 0.99 (s, 3H, CH3-17), 0.91 (s, $\left.3 \mathrm{H}, \mathrm{CH}_{3}-19\right), 0.79$ (s, 3H, $\left.\mathrm{CH}_{3}-20\right) ;{ }^{13} \mathrm{C}$ NMR $\left(100 \mathrm{MHz}, \mathrm{CDCl}_{3},\right) \delta$ $158.65,157.77,136.74,135.13,76.55,61.17,52.83,50.08,49.01$, 43.76, 38.57, 37.36, 36.99, 36.94, 35.92, 33.22, 25.03, 20.35, 20.29, 17.78, 17.62, 15.63; ESI-HRMS (negative) m/z: calcd. for $\mathrm{C}_{22} \mathrm{H}_{31} \mathrm{O}_{4}$ 359.22278, found $359.22245[\mathrm{M}-\mathrm{H}]$. 


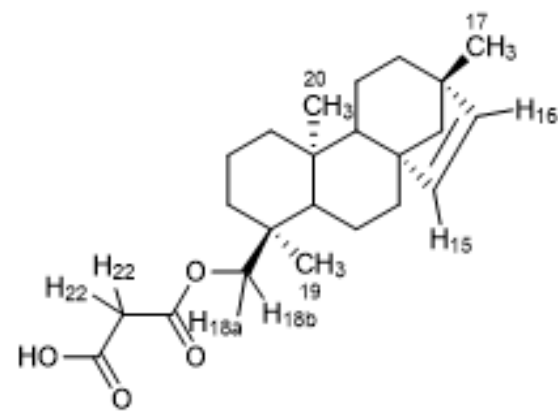

3

3. ent-beyer-15-en-18-0-malonate. White oil (yield 10\%); $[\alpha]_{D}+25.8^{\circ}$ $\left(\mathrm{CHCl}_{3}\right) ;{ }^{1} \mathrm{H}$ NMR $\left(400 \mathrm{MHz}, \mathrm{CDCl}_{3}\right.$, $) 5.67(\mathrm{~d}, 1 \mathrm{H}, \mathrm{J}=5.6 \mathrm{~Hz} \mathrm{H}-15), 5.45$ (d, $1 \mathrm{H}, \mathrm{J}=5.6 \mathrm{~Hz}, \mathrm{H}-16), 3.98$ (d, 1H, J=10.8 Hz, H-18a), 3.75 (d, 1H, J= $10.08 \mathrm{~Hz}, \mathrm{H}-18 \mathrm{~b}$ ), 3.45 (s, 2H, H-22 ), 0.99 (s, 3H, $\mathrm{CH}_{3}-17$ ), 0.85 (s, 3H, $\left.\mathrm{CH}_{3}-19\right), 0.78$ (s, 3H, $\left.\mathrm{CH}_{3}-20\right) ;{ }^{13} \mathrm{C}$ NMR $\left(100 \mathrm{MHz}, \mathrm{CDCl}_{3},\right) \delta$ 169.30, $167.81,136.66,135.19,74.66,61.23,52.92,49.89,43.76,38.70,37.32$, $36.98,36.77,35.95,33.26,25.05,22.83,20.30,20.24,17.86,17.72$, 15.63; ESI-HRMS (negative) m/z: calcd. for $\mathrm{C}_{23} \mathrm{H}_{33} \mathrm{O}_{4} 373.23843$, found $373.23862[\mathrm{M}-\mathrm{H}]^{-}$. 


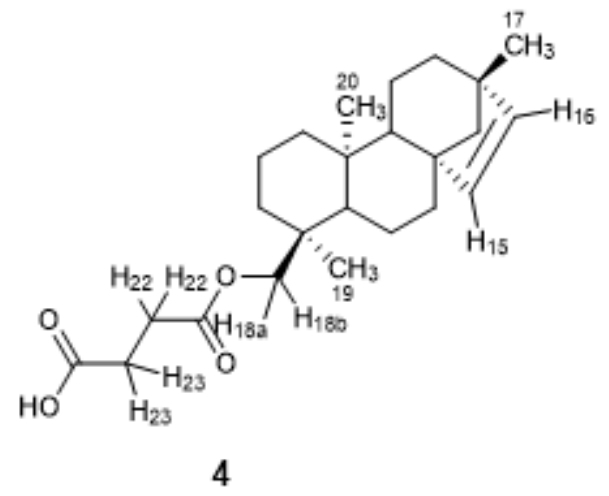

4. ent-beyer-15-en-18-0-succinate. Brown powder (yield 20\%); m.p. $107.5 \stackrel{\circ}{\circ} \pm 0.5 \stackrel{\circ}{ } \mathrm{C} ;[\alpha]_{\mathrm{D}}+14.6^{\circ}\left(\mathrm{CHCl}_{3}\right) ;{ }^{1} \mathrm{H}$ NMR $\left(400 \mathrm{MHz}, \mathrm{CDCl}_{3},\right) \delta 5.67$ (d, $1 \mathrm{H}, \mathrm{J}=5.6 \mathrm{~Hz}, \mathrm{H}-15), 5.45(\mathrm{~d}, 1 \mathrm{H}, \mathrm{J}=5.6 \mathrm{~Hz}, \mathrm{H}-16), 3.88$ (d, 1H, J= $10.8 \mathrm{~Hz}, \mathrm{H}-18 \mathrm{a}), 3.68$ (d, 1H, J=10.08 Hz, H-18b), 2.67 (m, 4H, H-22,H23), 0.99 (s, 3H, $\mathrm{CH}_{3}-17$ ), 0.83 (s, 3H, $\mathrm{CH}_{3}-19$ ), 0.77 (s, 3H, $\left.\mathrm{CH}_{3}-20\right) ;{ }^{13} \mathrm{C}$

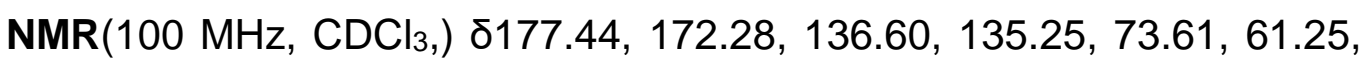
$52.93,50.01,49.05,43.75,38.74,37.30,37.06,36.70,36.01,33.27$, 29.20, 29.07, 25.06, 20.31, 20.20, 17.92, 17.80, 15.64; ESI-HRMS (negative) m/z: calcd. for $\mathrm{C}_{24} \mathrm{H}_{35} \mathrm{O}_{4} 387.25408$, found 387.25427 [M-H]' 


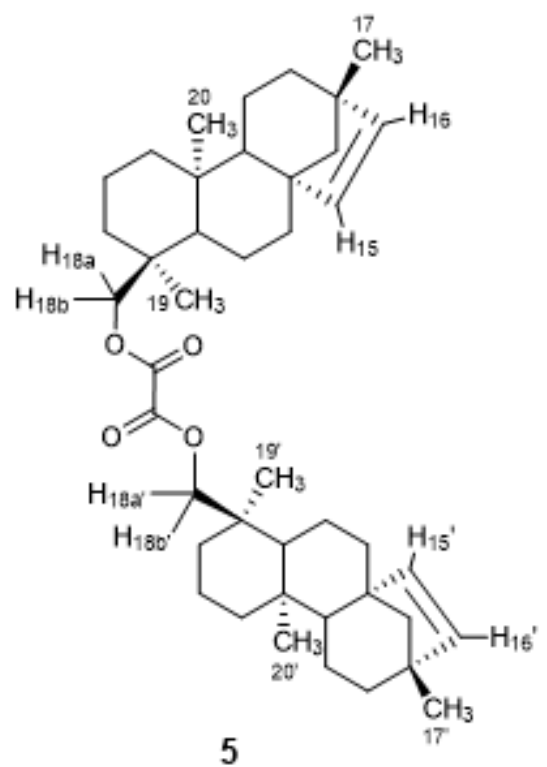

5. ent-beyer-15-en-18-0-oxaloyl dimer. Oil (yield 0.45\%); ${ }^{1} \mathrm{H}$ NMR (400 $\left.\mathrm{MHz}, \mathrm{CDCl}_{3}\right) \delta 5.68$ (d, 2H, J=5.6 Hz, H-16, H-16'), 5.46 (d, 2H, J=5.6 $\left.\mathrm{Hz}, \mathrm{H}-15, \mathrm{H}-15^{\prime}\right), 4.12$ (d, 2H, J=10.8 Hz, H-18a, H-18a'), 3.79 (d, 2H, J= $10.8 \mathrm{~Hz}, \mathrm{H}-18 \mathrm{~b}, \mathrm{H}-18 \mathrm{~b}$ ), 0.99 (s, 6H, $\mathrm{CH}_{3}-17, \mathrm{CH}_{3}-17$ '), 0.90 (s, 6H, $\mathrm{CH}_{3}-$ 19, $\left.\mathrm{CH}_{3}-19^{\prime}\right), 0.80$ (s, 6H, CH $3-20$ e $\left.\mathrm{CH}_{3}-20^{\prime}\right) ;{ }^{13} \mathrm{C}$ NMR $(100 \mathrm{MHz}$, $\left.\mathrm{CDCl}_{3}\right) \delta 158.08,136.69,135.12,74.95,61.20,52.98,49.66,49.04$, $43.73,38.82,37.38,37.04,36.89,35.99,33.29,25.04,20.31,20.19$, 17.93, 17.83, 15.66; ESI-HRMS (positive) m/z: calcd. for $\mathrm{C}_{42} \mathrm{H}_{62} \mathrm{O}_{4} \mathrm{Na}$ 653.45403 , found $653.45408[\mathrm{M}+\mathrm{Na}]^{+}$. 


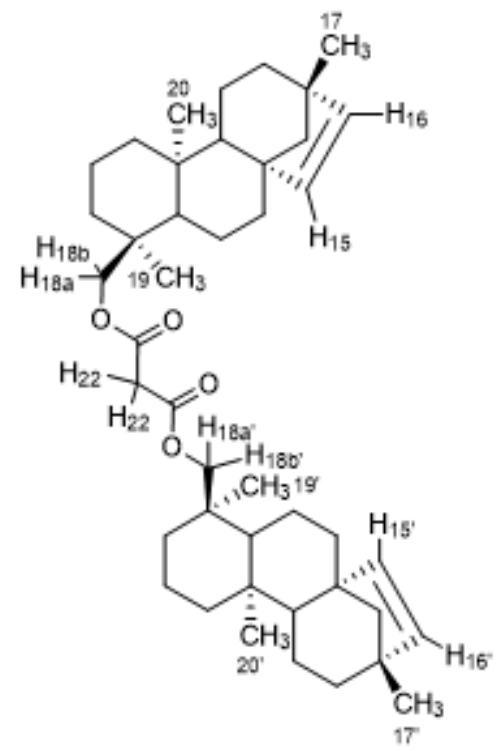

6

6.. ent-beyer-15-en-18-0-malonoyl dimer. Oil (yield 0.48\%); ${ }^{1} \mathbf{H}$ NMR (400 MHz, $\mathrm{CDCl}_{3}$ ) $) 5.67$ (d, 2H, J=5.6 Hz, H-16, H-16'), 5.45 (d, 2H, J= $5.6 \mathrm{~Hz}, \mathrm{H}-15, \mathrm{H}-15$ '), 3.91 (d, 2H, J=10.8 Hz, H-18a, H-18a'), 3.78 (d, $\left.2 \mathrm{H}, \mathrm{J}=10.8 \mathrm{~Hz}, \mathrm{H}-18 \mathrm{~b}, \mathrm{H}-18 \mathrm{~b}^{\prime}\right), 3.41$ (s, 2H, H-22), 0.99 (s, 6H, CH $\mathrm{CH}_{3}-17$, $\mathrm{CH}_{3}-17$ '), 0.86 (s, 6H, CH $3-19, \mathrm{CH}_{3}-19$ '), 0.78 (s, 6H, CH $3-20, \mathrm{CH}_{3}-20$ '); ${ }^{13} \mathrm{C}$ NMR $\left(100 \mathrm{MHz}, \mathrm{CDCl}_{3}\right.$ ) $\delta 166.84,136.64,135.23,74.39,61.28$, $52.95,50.11,49.05,43.77,41.97,38.72,37.31,37.04,36.72,36.01$, 33.28, 25.06, 20.30, 20.26, 17.89, 17.75, 15.63; ESI-HRMS (positive ) $\mathrm{m} / \mathrm{z}$ : calcd for $\mathrm{C}_{43} \mathrm{H}_{64} \mathrm{O}_{4} \mathrm{Na} 667.46968$, found $667.46911[\mathrm{M}+\mathrm{Na}]^{+}$. 


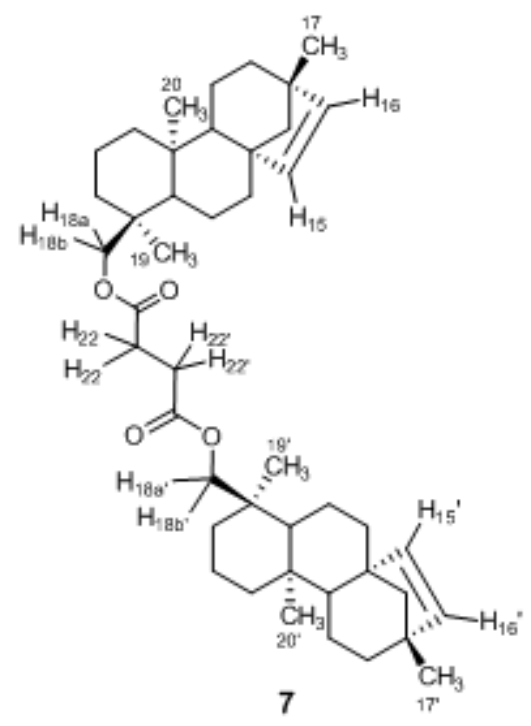

7. ent-beyer-15-en-18-0-succinoyl dimer. White powder (yield $0.25 \%$ ). m.p. $123 \stackrel{\circ}{\circ} \mathrm{C} \pm 0.5^{\circ} \mathrm{C} ;{ }^{1} \mathrm{H}$ NMR $\left(400 \mathrm{MHz}, \mathrm{CDCl}_{3}\right) \delta 5.68(\mathrm{~d}, 2 \mathrm{H}, \mathrm{J}=5.2$ $\mathrm{Hz}, \mathrm{H}-16, \mathrm{H}-16$ '), 5.45 (d, 2H, J=5.2 Hz, H-15, H-15'), 3.88 (d, 2H, J= $10.4 \mathrm{~Hz}, \mathrm{H}-18 \mathrm{a}, \mathrm{H}-18 \mathrm{a}$ )), 3.68 (d, 2H, J=10.4 Hz, H-18b, H-18b'), 2.66 (s, 4H, H-22, H-22'); 0.99 (s, 6H, CH $\mathrm{CH}_{3}-17, \mathrm{CH}_{3}-17$ '), 0.84 (s, 6H, $\mathrm{CH}_{3}-19$, $\left.\mathrm{CH}_{3}-19^{\prime}\right), 0.78$ (s, 6H, CH $\left.3-20, \mathrm{CH}_{3}-20^{\prime}\right) ;{ }^{13} \mathrm{C} \mathrm{NMR}\left(100 \mathrm{MHz}, \mathrm{CDCl}_{3}\right) \delta$ 172.45, 136.61, 135.27, 73.61, 61.27, 52.95, 50.11, 49.07, 43.77, 38.78, $37.31,37.09,36.70,36.07,33.28,32.08,29.51,25.07,22.85,20.31$, 20.24, 17.94, 17.82, 15.65; ESI-HRMS (positive) m/z: calcd.for $\mathrm{C}_{44} \mathrm{H}_{66} \mathrm{O}_{4} \mathrm{Na} 681.48533$, found $681.48580[\mathrm{M}+\mathrm{Na}]^{+}$. 


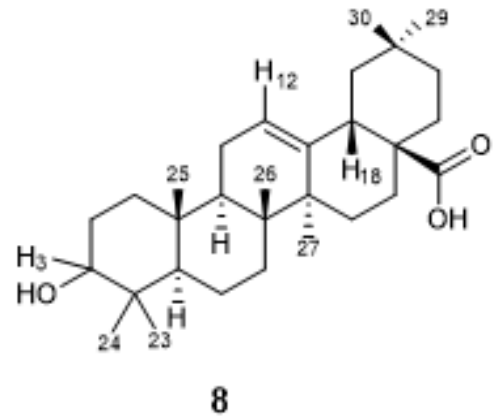

8. Oleanolic acid. White powder (yield $2 \%$ ); m.p. $309^{\circ} \mathrm{C} \pm 0.5^{\circ} \mathrm{C} ;{ }^{1} \mathbf{H}$ NMR $\left(400 \mathrm{MHz}, \mathrm{CDCl}_{3}\right) \delta 5.28(\mathrm{t}, 1 \mathrm{H}, \mathrm{J}=3.4 \mathrm{~Hz}, \mathrm{H}-12), 3.22$ (dd, $1 \mathrm{H}$, $J=10.8,4.4 \mathrm{~Hz}, \mathrm{H}-3$ ), 2.82 (dd, $1 \mathrm{H} \mathrm{J}=14,4.4 \mathrm{~Hz}, \mathrm{H}-18), 1.13$ (s, 3H, $\mathrm{CH}_{3}-$ 27), 0.99 (s, 3H, $\left.\mathrm{CH}_{3}-23\right), 0.93$ (s, 3H, $\left.\mathrm{CH}_{3}-25\right), 0.91$ (s, 3H, $\mathrm{CH}_{3}-30$ ), 0.90 (s, 3H, CH $\mathrm{CH}_{3}-29$ ), 0.77 (s, 3H, $\left.\mathrm{CH}_{3}-24\right), 0.75$ (s, 3H, $\left.\mathrm{CH}_{3}-26\right) ;{ }^{13} \mathrm{C}$ NMR $\left(100 \mathrm{MHz}, \mathrm{CDCl}_{3}\right)$ ) $\delta 183.06,143.73,122.80,79.19,55.38,47.79$, 46.68, 41.77, 41.17, 39.43, 38.91, 37.24, 33.96, 33.21, 32.79, 32.59, $30.82,28.25,27.84,26.08,23.72,18.46,17.25,15.69,15.47$; ESI-MS (negative) m/z: calcd. for $\mathrm{C}_{30} \mathrm{H}_{47} \mathrm{O}_{3} 455$, found $455.3[\mathrm{M}-\mathrm{H}]^{-}$. 


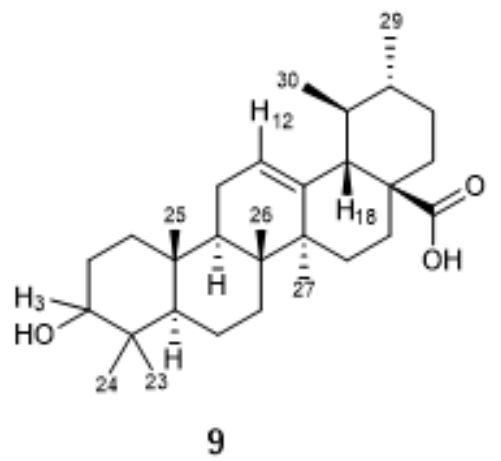

9. Ursolic acid. powder (yield 1\%); m.p. $284{ }^{\circ} \mathrm{C} \pm 0.5{ }^{\circ} \mathrm{C}$; ${ }^{1} \mathbf{H}$ NMR (DMSO-d6, $400 \mathrm{MHz}$ ) $\delta 5.12$ (s, 1H,H-12), 3.00 (s, 1H, H-3), 1.04 (s, 3H, $\mathrm{CH}_{3}-27$ ), 0.91 (s, 3H, $\mathrm{CH}_{3}-30$ ), 0.89 (s, 3H, $\mathrm{CH}_{3}-23$ ), 0.86 (s, 3H, $\mathrm{CH}_{3}-$ 25), 0.81 (d, 3H, $\mathrm{CH}_{3}-29$ ), 0.74 (s, 3H, $\left.\mathrm{CH}_{3}-24\right), 0.67$ (s, 3H, $\mathrm{CH}_{3}-26$ ); ${ }^{13} \mathrm{C}$-NMR $(100 \mathrm{MHz}$, DMSO-d 6 ) $\delta$ 178.28, 138.19, 124.58, 76.83, 54.78, 52.37, 47.01, 46.82, 41.64, 38.50, 38.44, 38.38, 38.23, 36.53, 36.31, 28.26, 26.99, 23.80, 23.27, 22.85, 21.08, 18.00, 17.01, 16.91, 16.08, 15.23; ESI-MS (negative) m/z: calcd. for $\mathrm{C}_{30} \mathrm{H}_{47} \mathrm{O}_{3} 455$, found 455.2 [M $\mathrm{H}]$. 


\subsection{3 ${ }^{1} \mathrm{H}$ and ${ }^{13} \mathrm{C}$ NMR spectra of compounds $1-9$}

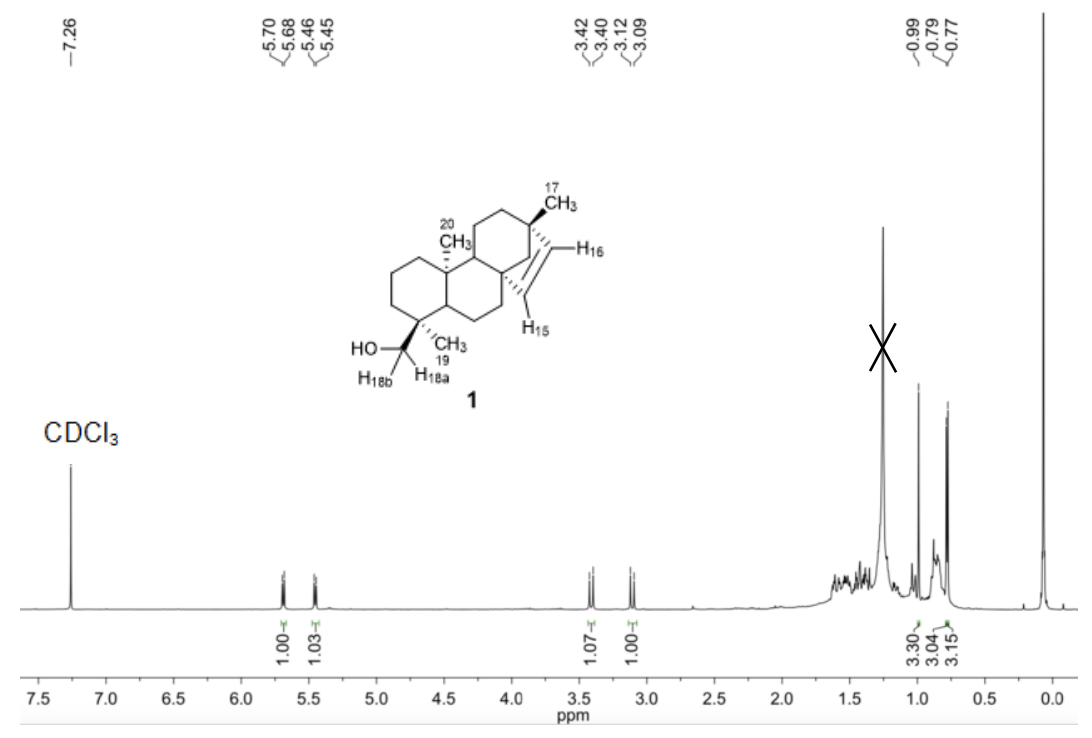

Figure S1. ${ }^{1} \mathrm{H} \mathrm{NMR}\left(\mathrm{CDCl}_{3}, 400 \mathrm{MHz}\right)$ spectrum of compound 1
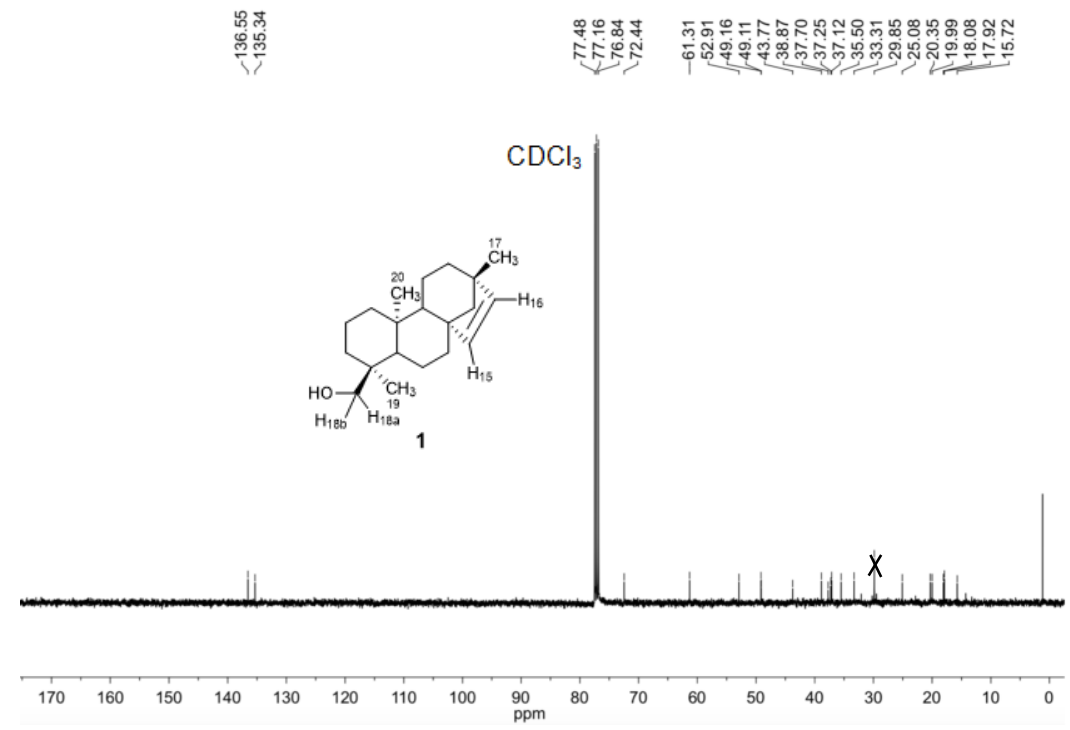

Figure S2. ${ }^{13} \mathrm{C} \mathrm{NMR}\left(\mathrm{CDCl}_{3}, 100 \mathrm{MHz}\right)$ spectrum of compound 1 


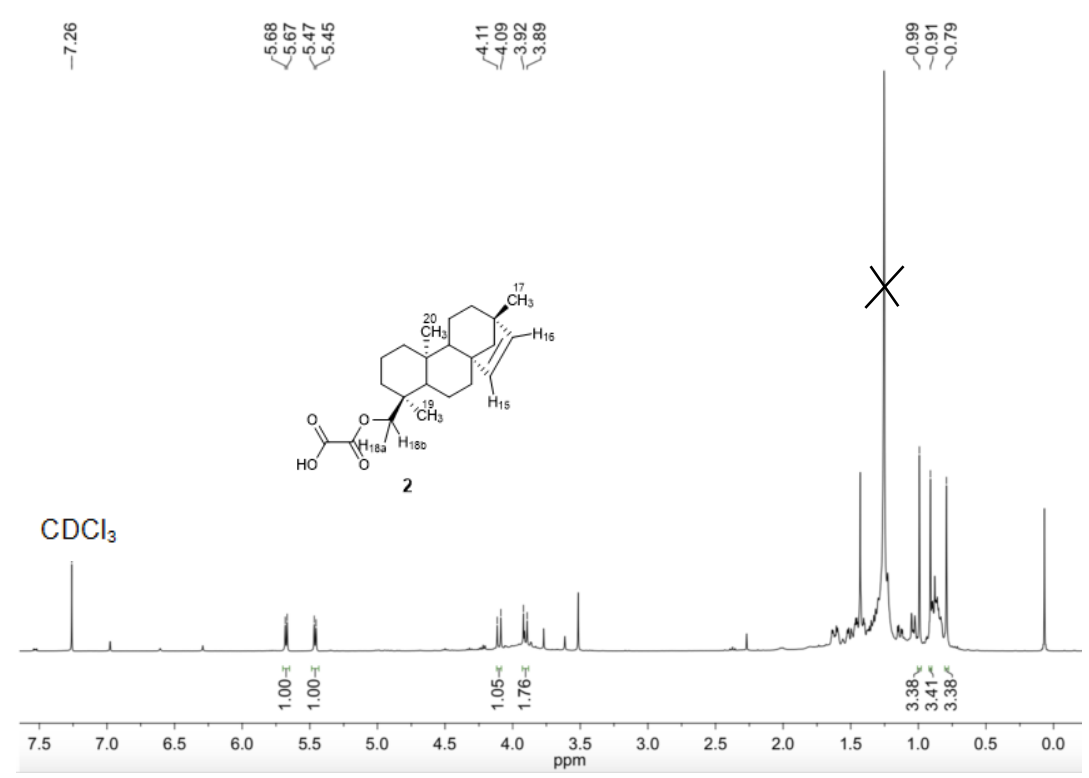

Figure S3. ${ }^{1} \mathrm{H}$ NMR $\left(\mathrm{CDCl}_{3}, 400 \mathrm{MHz}\right)$ spectrum of compound 2

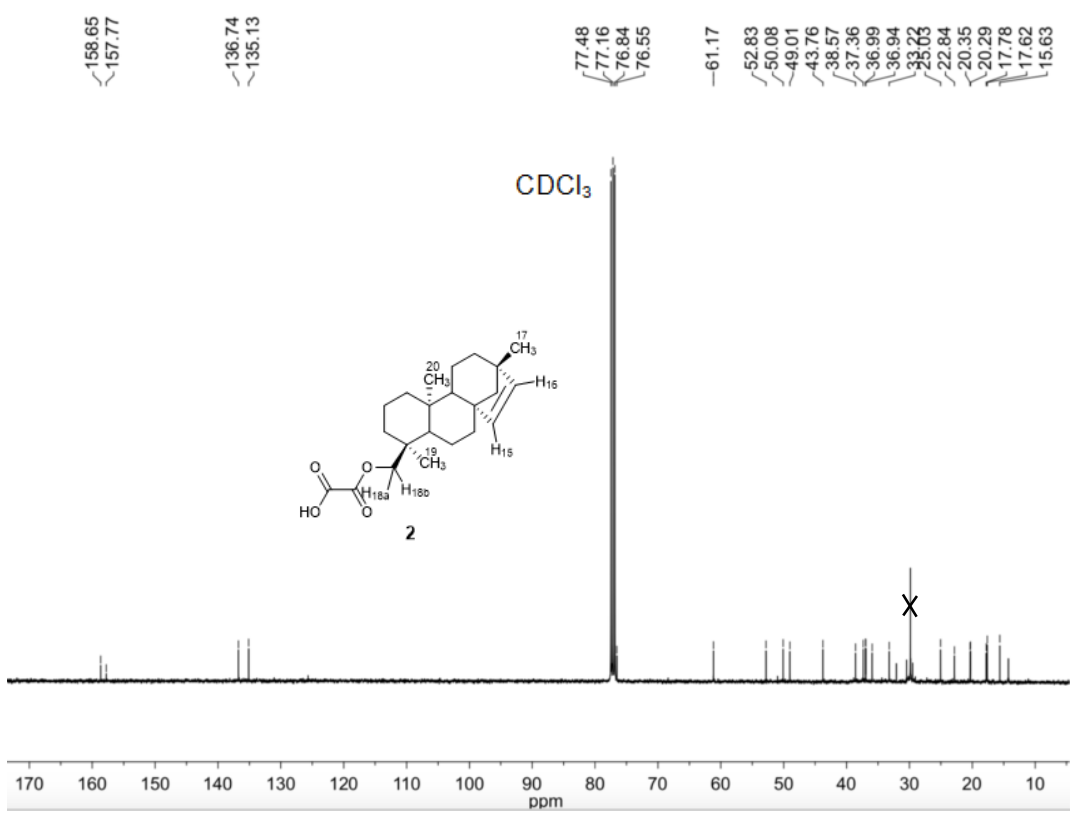

Figure S4. ${ }^{13} \mathrm{C} \mathrm{NMR}\left(\mathrm{CDCl}_{3}, 100 \mathrm{MHz}\right)$ spectrum of compound 2 


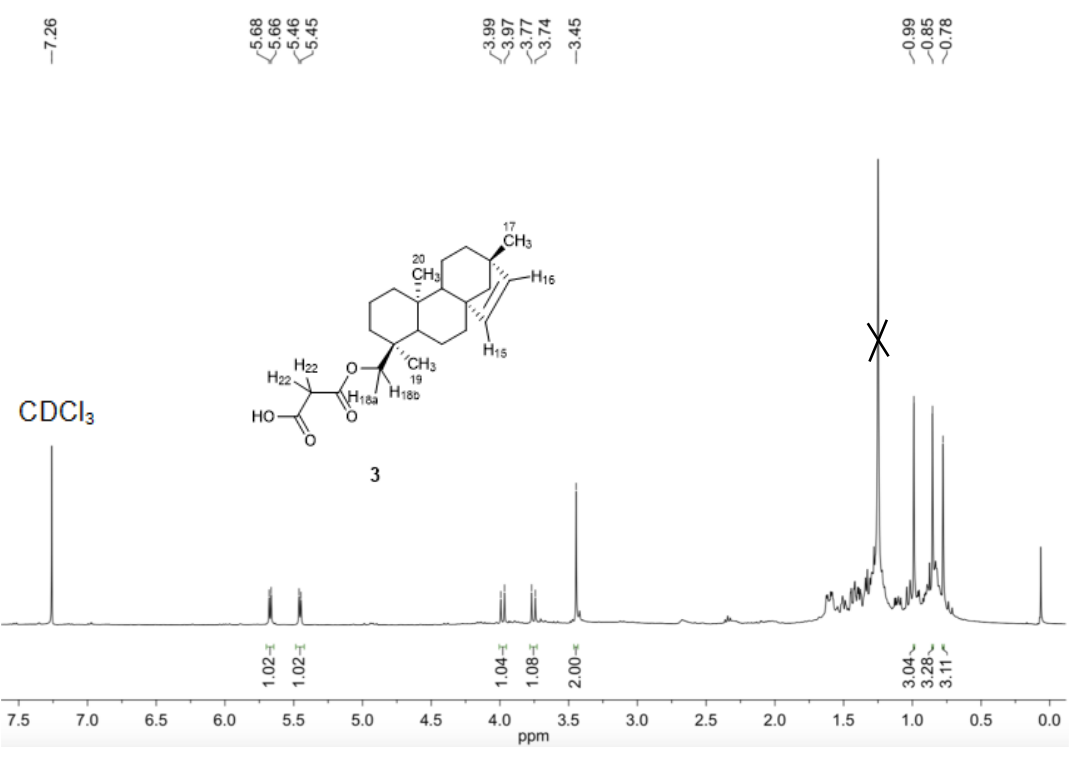

Figure S5. ${ }^{1} \mathrm{H} \mathrm{NMR}\left(\mathrm{CDCl}_{3}, 400 \mathrm{MHz}\right)$ spectrum of compound 3

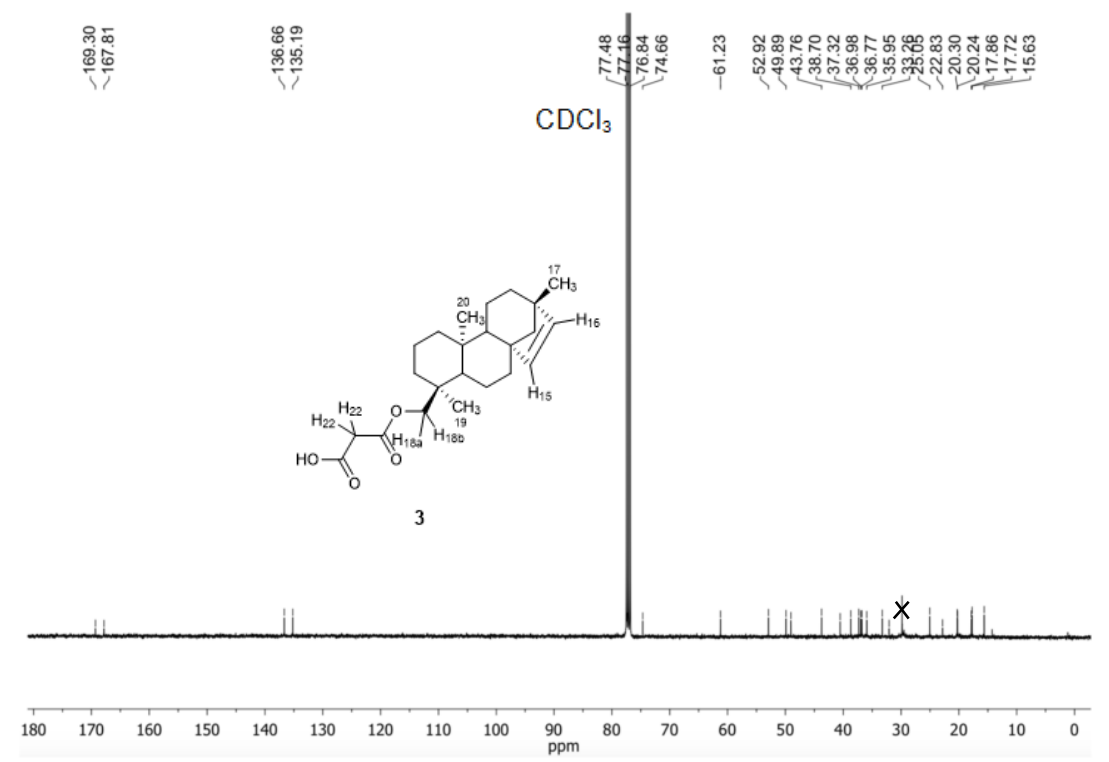

Figure S6. ${ }^{13} \mathrm{C} \mathrm{NMR}\left(\mathrm{CDCl}_{3}, 100 \mathrm{MHz}\right)$ spectrum of compound 3 


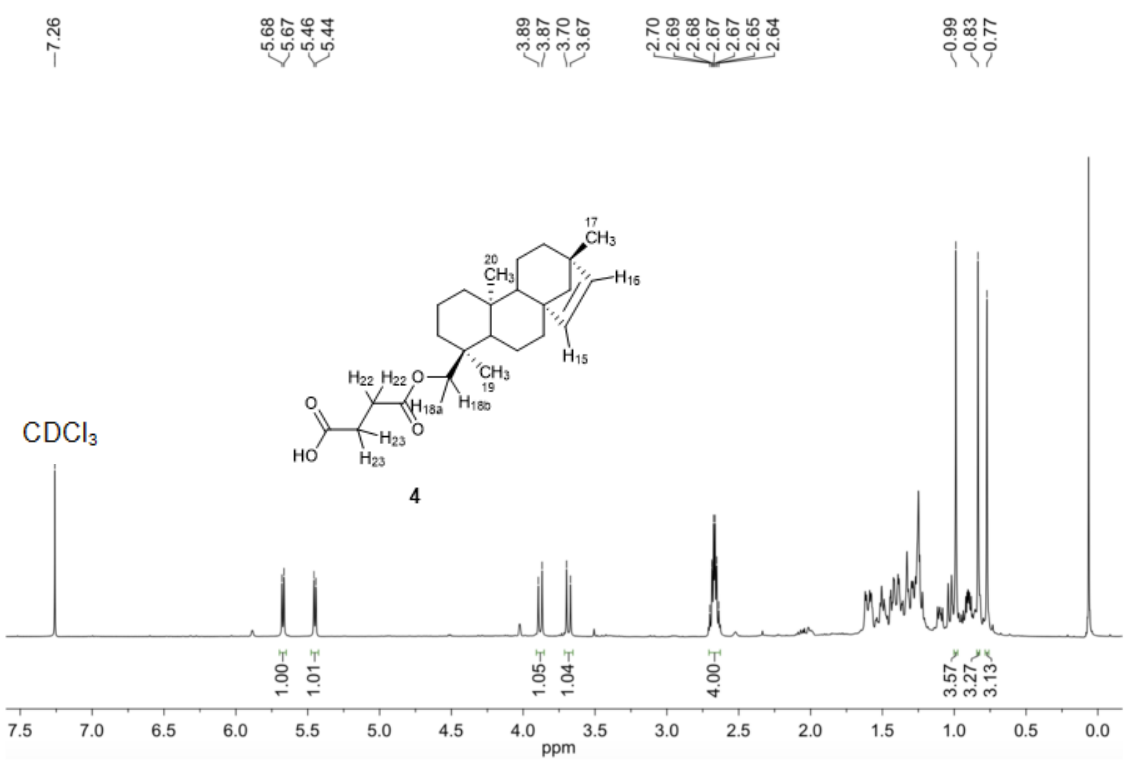

Figure S7. ${ }^{1} \mathrm{H} \mathrm{NMR}\left(\mathrm{CDCl}_{3}, 400 \mathrm{MHz}\right)$ spectrum of compound 4

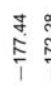

迹
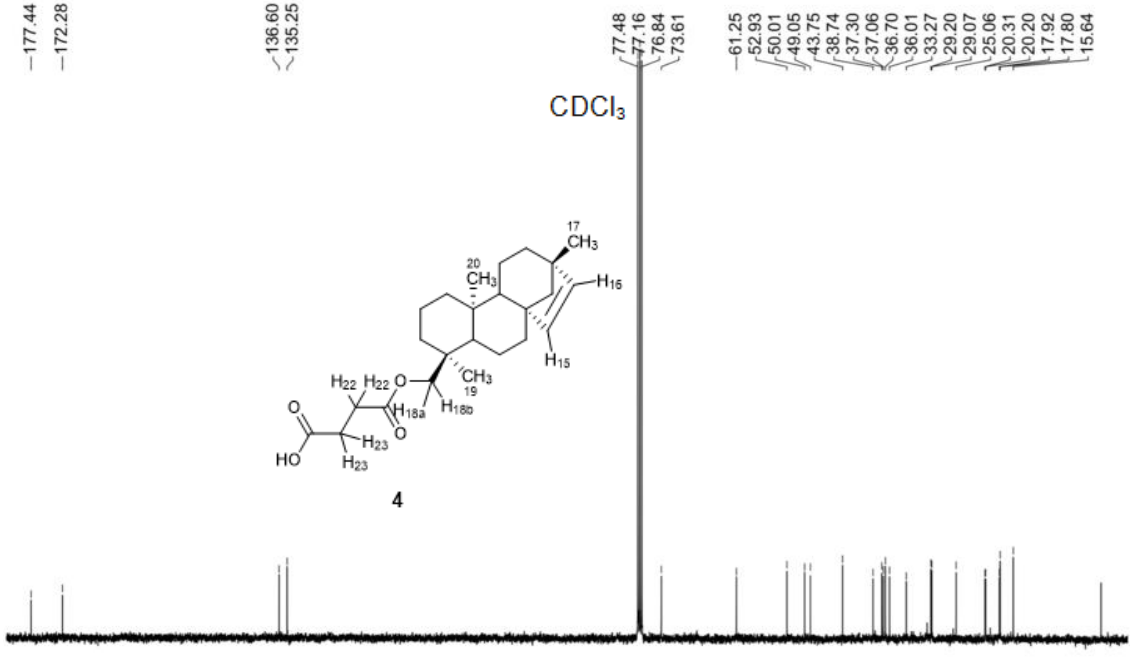

$\begin{array}{lllllllllllllllllll}180 & 170 & 160 & 150 & 140 & 130 & 120 & 110 & 100 & 90 & 80 & 70 & 60 & 50 & 40 & 30 & 20 & 10 & 0\end{array}$

Figure S8. ${ }^{13} \mathrm{C}$ NMR $\left(\mathrm{CDCl}_{3}, 100 \mathrm{MHz}\right)$ spectrum of compound 4 


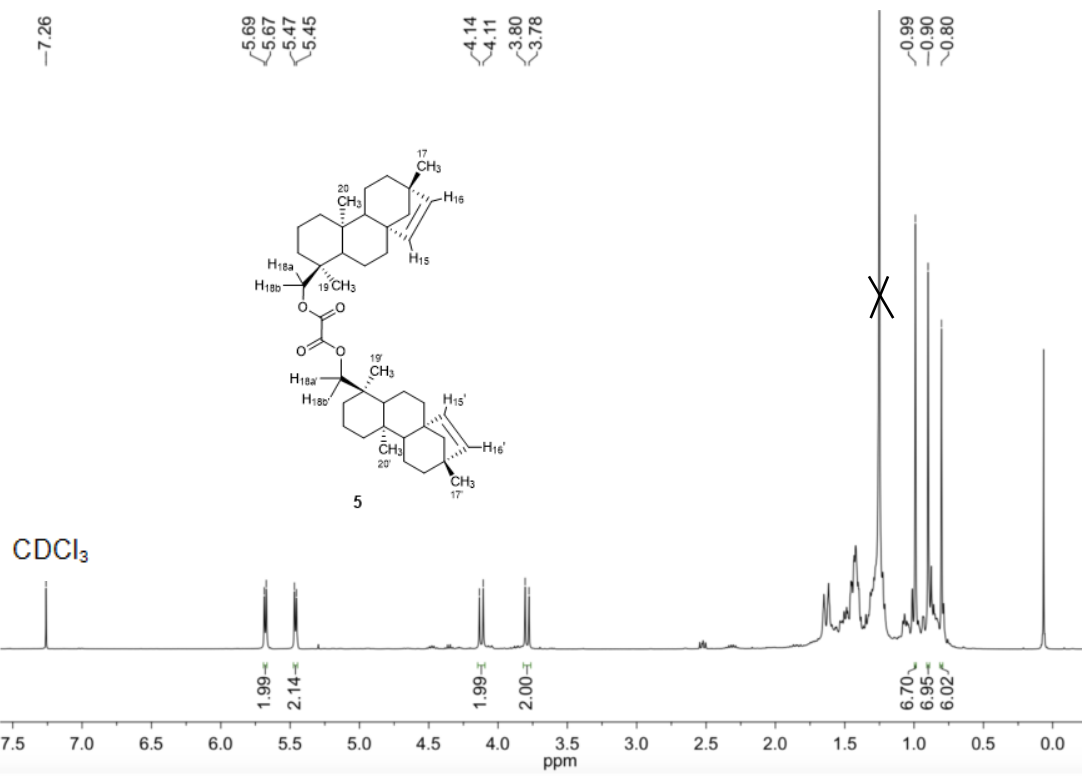

Figure S9. ${ }^{1} \mathrm{H} \mathrm{NMR}\left(\mathrm{CDCl}_{3}, 400 \mathrm{MHz}\right)$ spectrum of compound $\mathbf{5}$

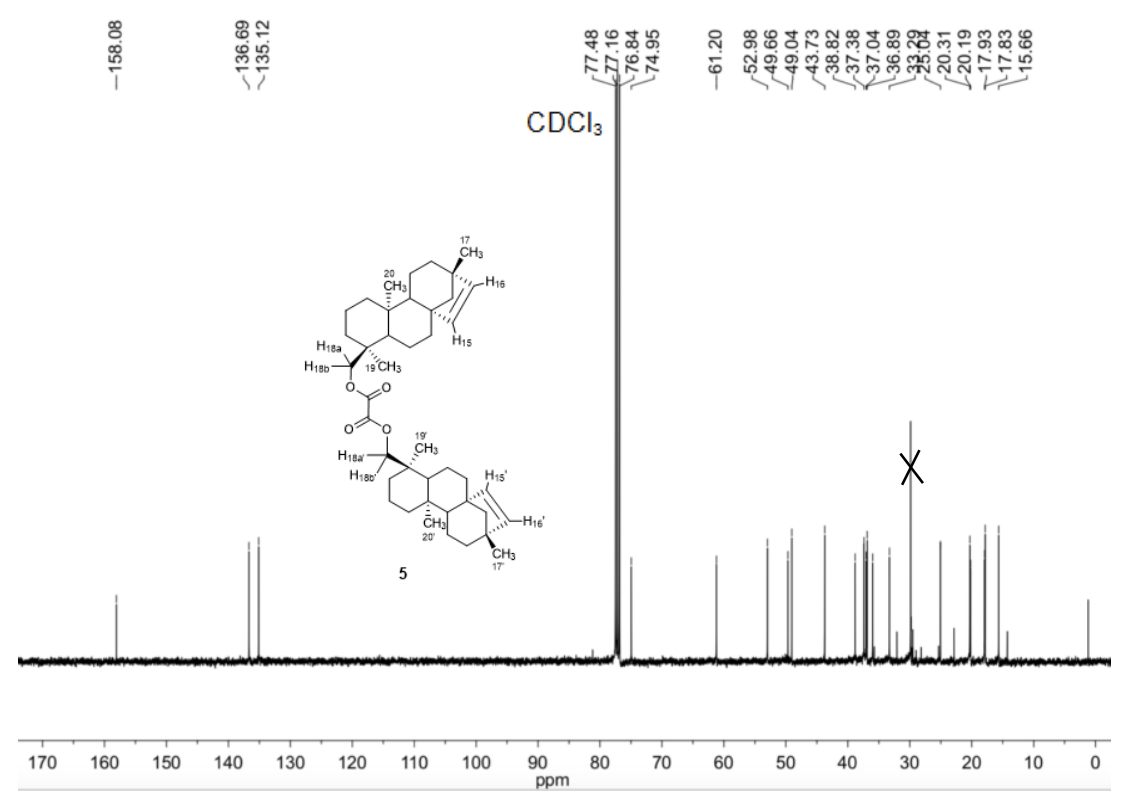

Figure S10. ${ }^{13} \mathrm{C}$ NMR $\left(\mathrm{CDCl}_{3}, 100 \mathrm{MHz}\right)$ spectrum of compound 5 


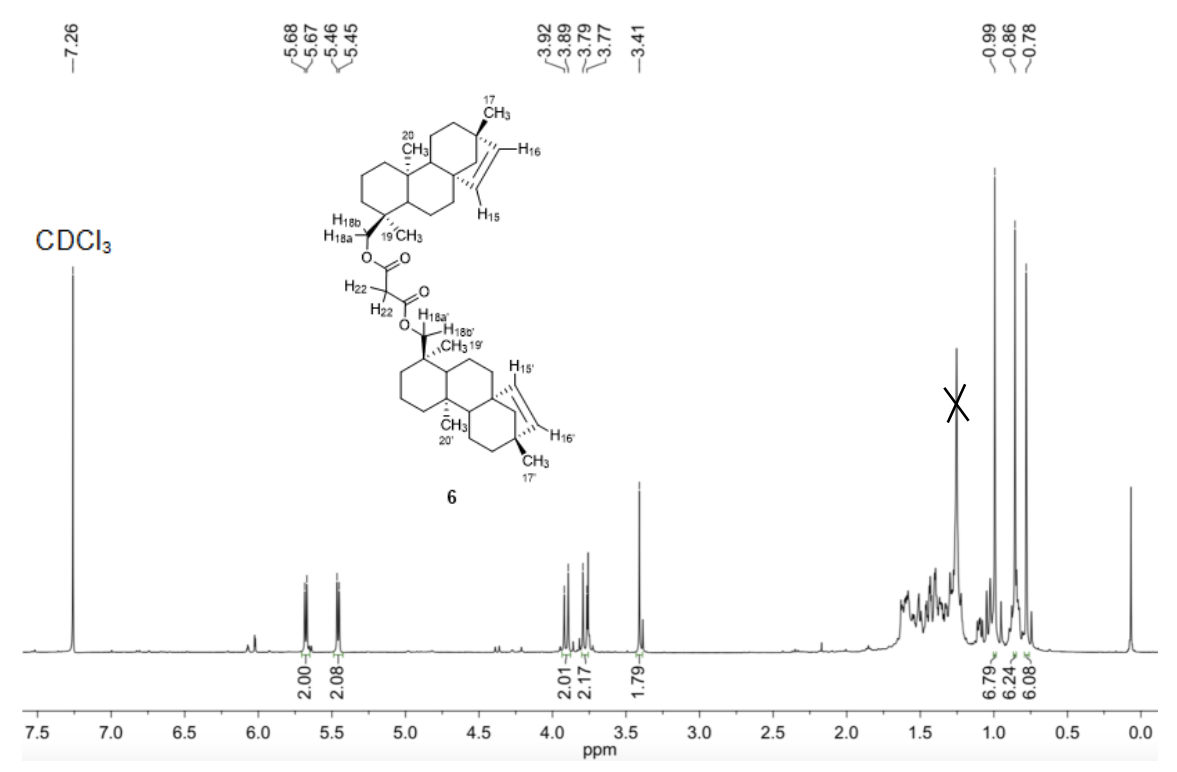

Figure S11. ${ }^{1} \mathrm{H} \mathrm{NMR}\left(\mathrm{CDCl}_{3}, 400 \mathrm{MHz}\right)$ spectrum of compound 6

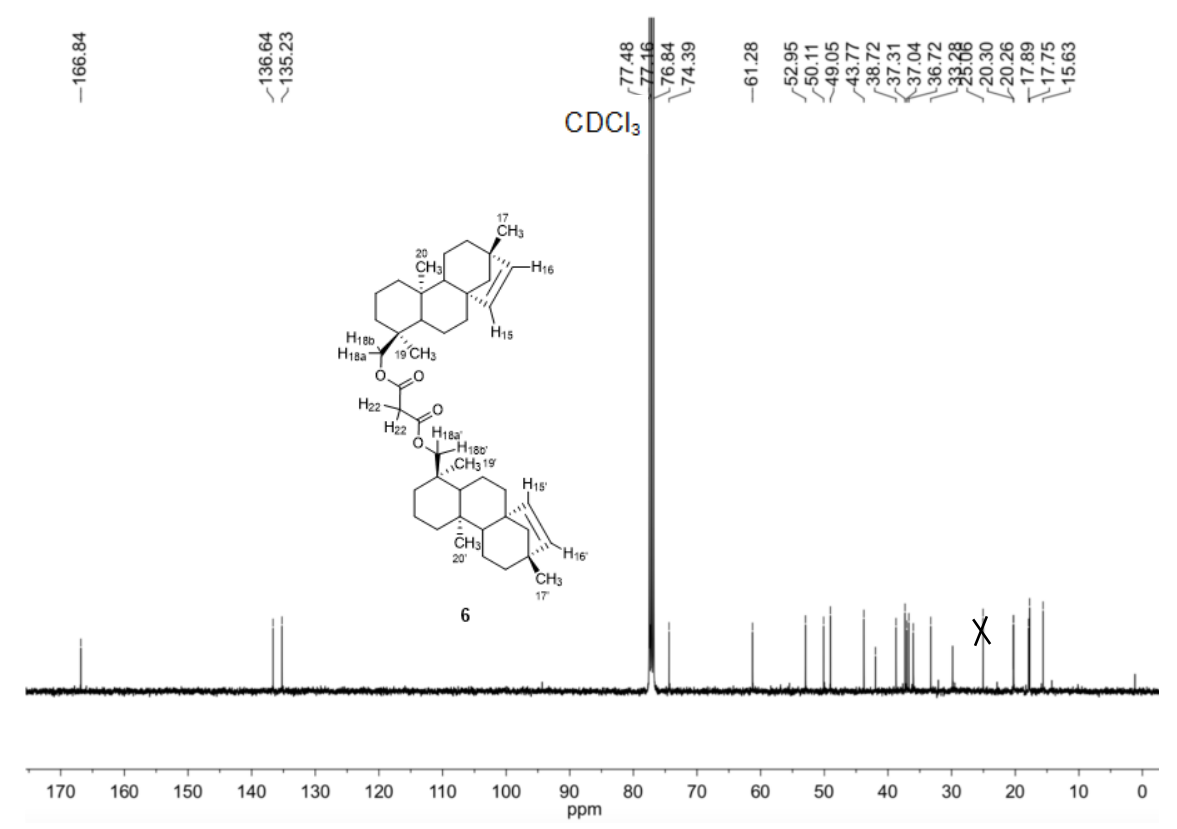

Figure $\mathbf{S 1 2 .}{ }^{13} \mathrm{C}$ NMR $\left(\mathrm{CDCl}_{3}, 100 \mathrm{MHz}\right)$ spectrum of compound 6 


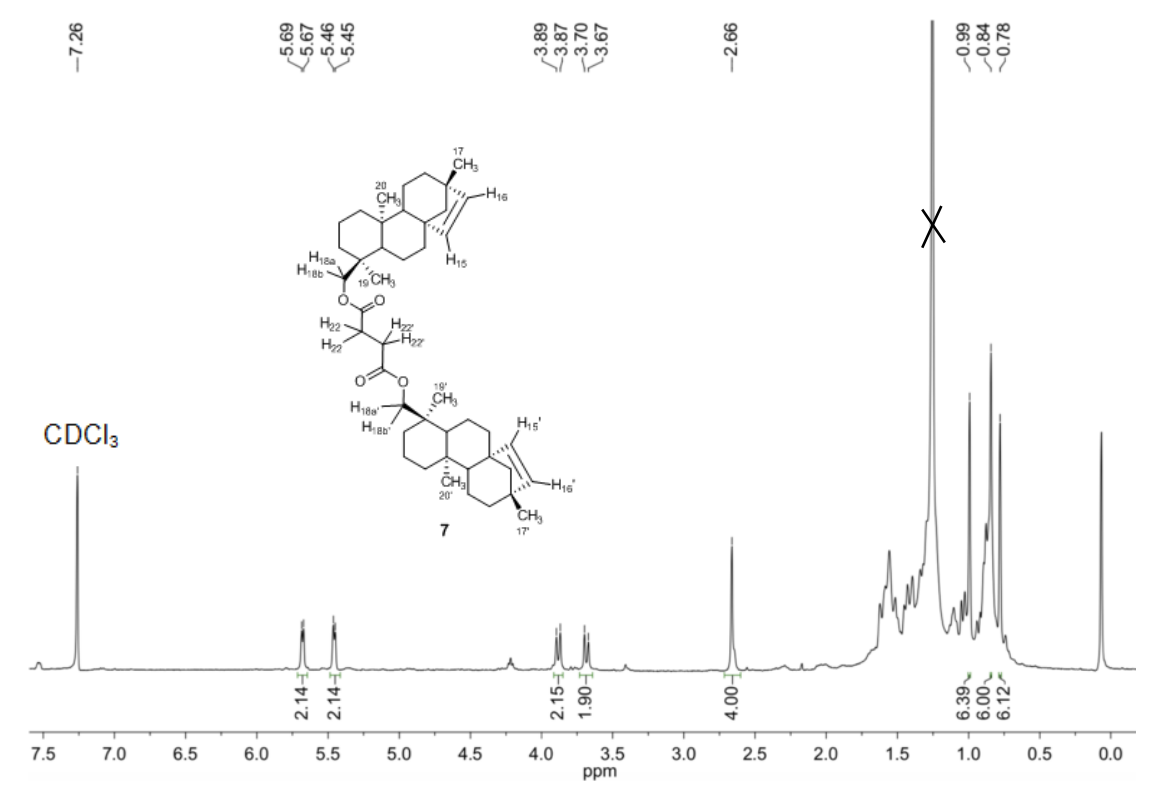

Figure S13. ${ }^{1} \mathrm{H} \mathrm{NMR}\left(\mathrm{CDCl}_{3}, 400 \mathrm{MHz}\right)$ spectrum of compound 7

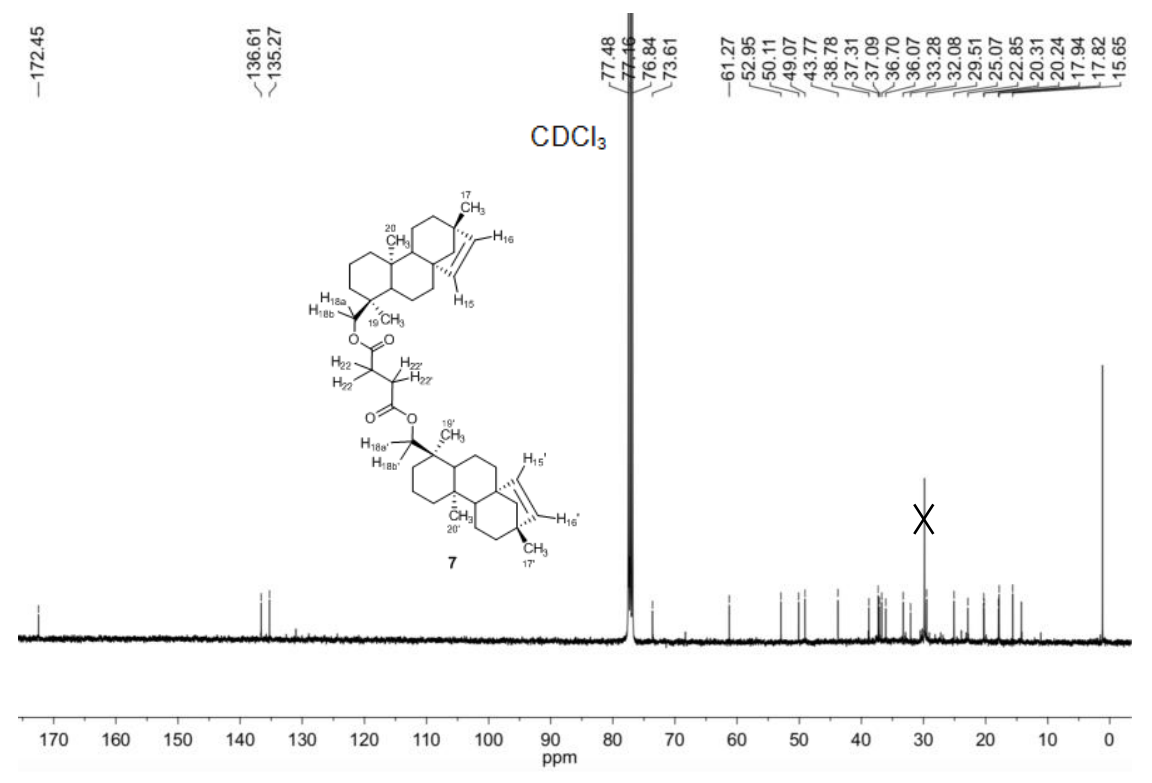

Figure S14. ${ }^{13} \mathrm{C}$ NMR $\left(\mathrm{CDCl}_{3}, 100 \mathrm{MHz}\right)$ spectrum of compound 7 


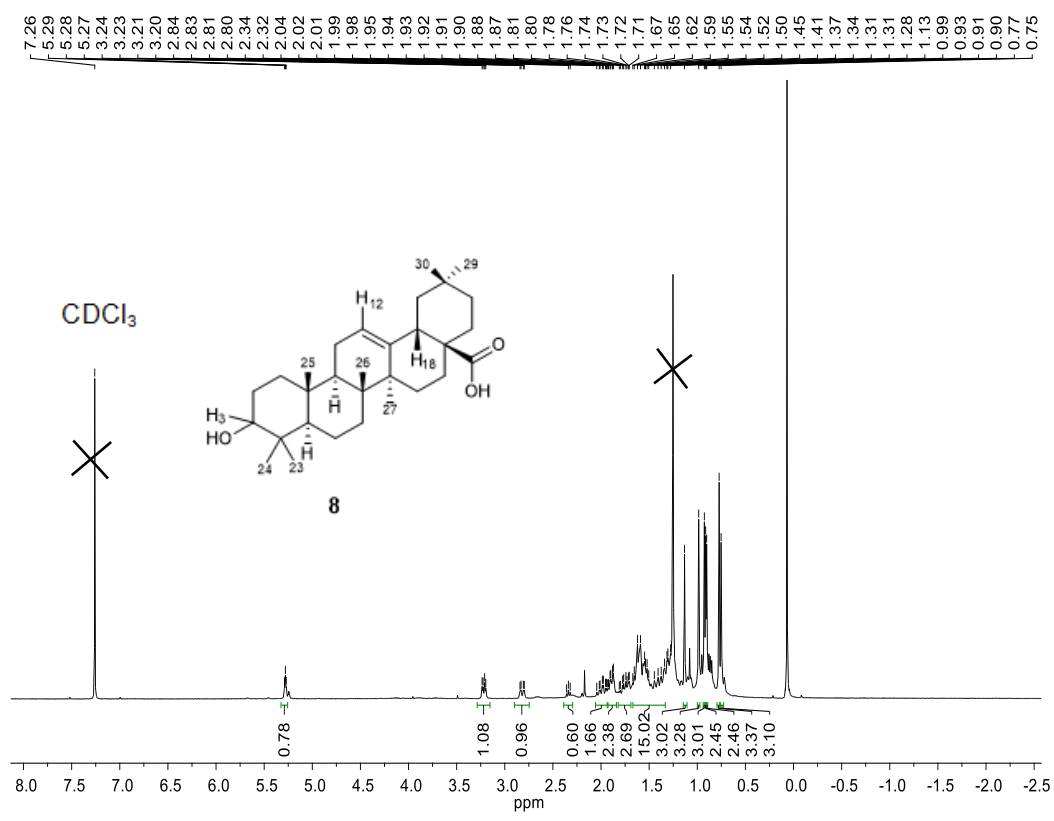

Figure S15. ${ }^{1} \mathrm{H} \mathrm{NMR}\left(\mathrm{CDCl}_{3}, 400 \mathrm{MHz}\right)$ spectrum of compound 8

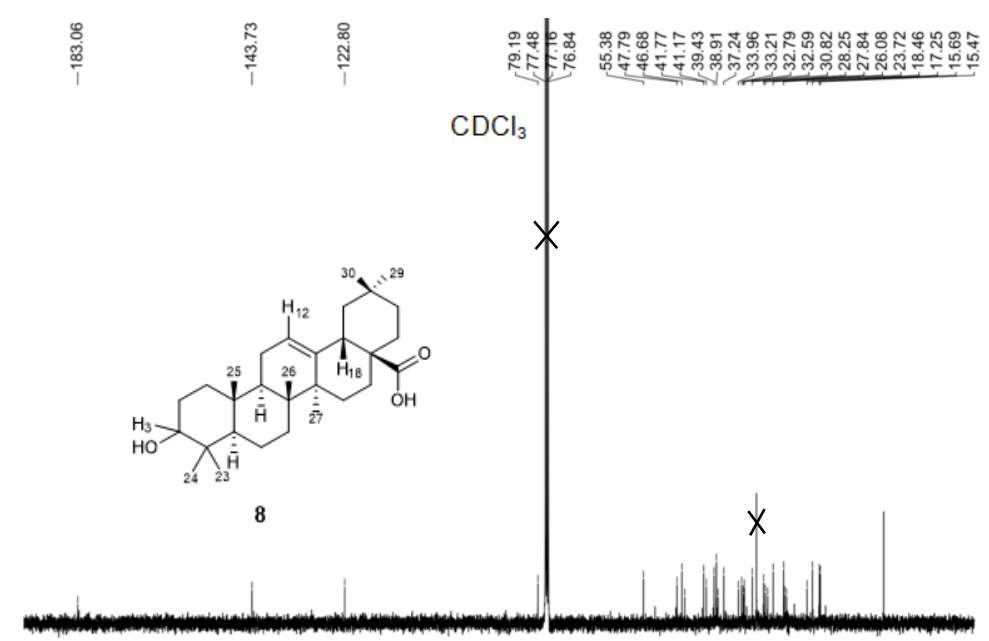

$190170 \quad 150 \quad 130 \quad 110 \begin{array}{lllllllllllll}\mathrm{ppm} & 90 & 80 & 70 & 60 & 50 & 40 & 30 & 20 & 10 & 0 & -10\end{array}$

Figure $\mathbf{S 1 6 .}{ }^{13} \mathrm{C} \mathrm{NMR}\left(\mathrm{CDCl}_{3}, 100 \mathrm{MHz}\right)$ spectrum of compound 8 


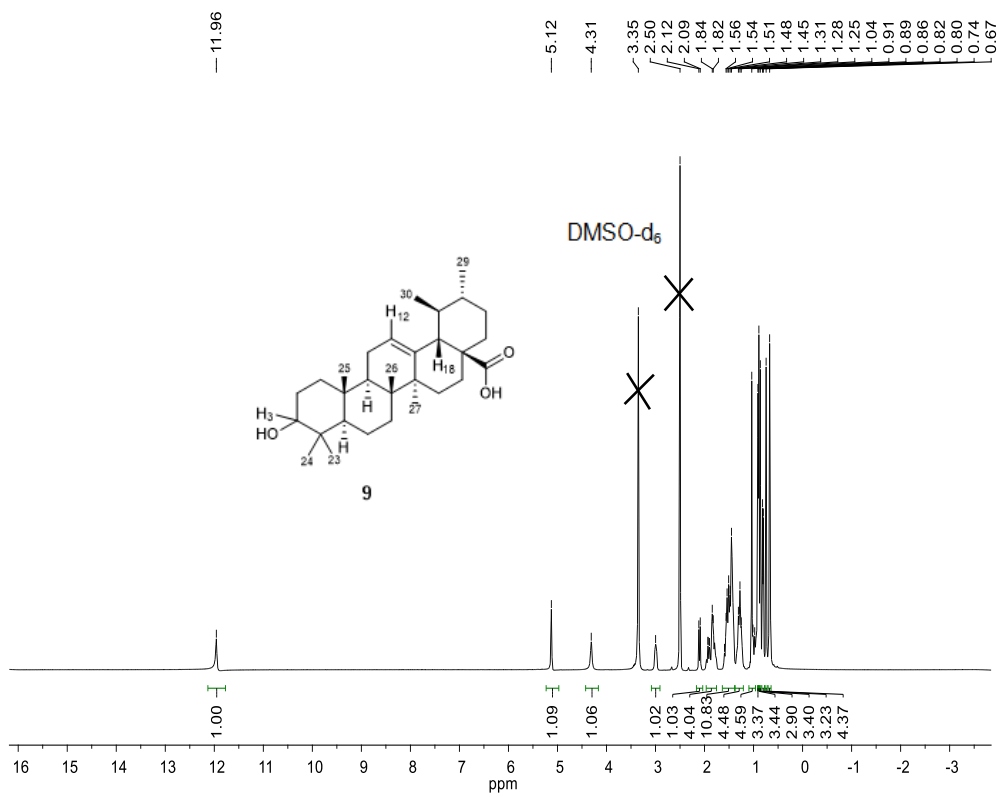

Figure S17. ${ }^{1} \mathrm{H}$ NMR (DMSO- $\mathrm{d}_{6}, 400 \mathrm{MHz}$ ) spectrum of compound 9
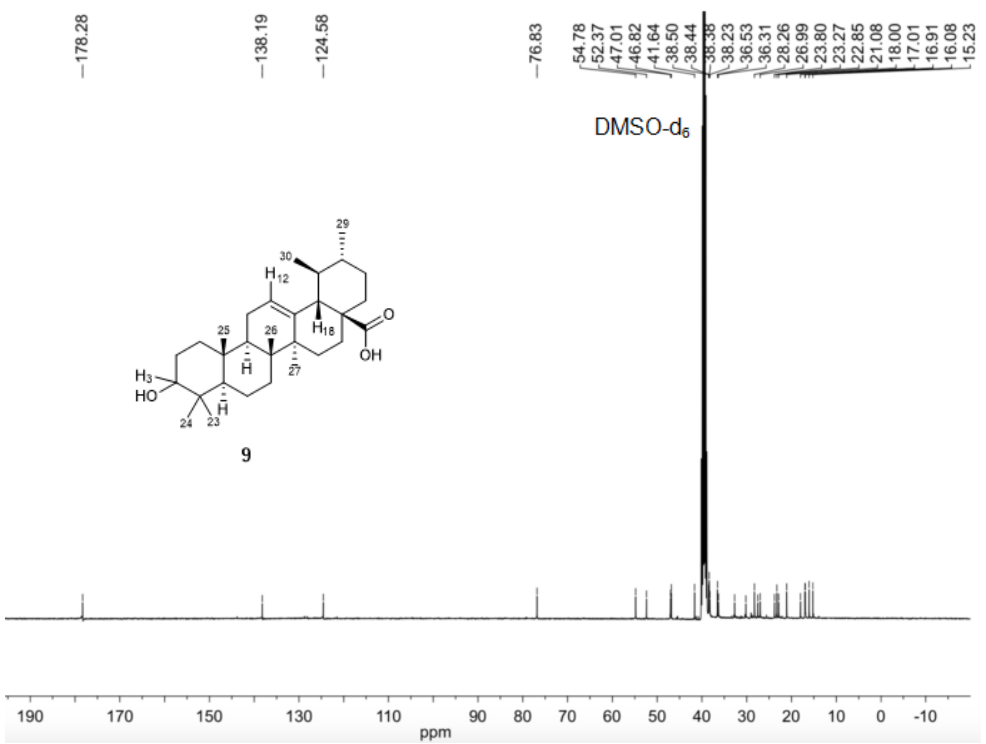

Figure S18. ${ }^{13} \mathrm{C}$ NMR (DMSO- $\mathrm{d}_{6}, 100 \mathrm{MHz}$ ) spectrum of compound 9 


\subsubsection{General procedure to synthesize compounds 2, 3, 4 from 1}

To a solution of 1 (0.346 mmol, $99 \mathrm{mg}, 1$ equiv.) in $\mathrm{Et}_{2} \mathrm{O}(1.80 \mathrm{ml})$ the corresponding acyl chloride $(0.693 \mathrm{mmol}, 4$ equiv.) was added dropwise at $0{ }^{\circ} \mathrm{C}$ and the reaction mixture was stirred at reflux for 30 minutes. Then the reaction mixture was cooled down and quenched by slow addition of distilled water. The aqueous layer was extracted with $\mathrm{Et}_{2} \mathrm{O}$ and the organic layer was washed with water for two times and with brine, dried over anhydrous $\mathrm{Na}_{2} \mathrm{SO}_{4}$ and evaporated to dryness under reduced pressure. The residue was purified by flash column chromatography on silica gel according to the experimental conditions described previously. The chemical identity of these compounds is assessed by NMR and HRMS experiments which proved to be in agreement with the data reported in paragraph 1.2.2.

\section{Biological assays}

\subsection{Bacterial strains and cell line}

The bacterial strains used in this study were the Gram-negative $P$. aeruginosa ATCC 27853 and E. coli ATCC 25922, and the Gram-positive S. aureus ATCC 25923, S. epidermidis ATCC 12228, B. megaterium Bm11 and B. thuringensis B15. 
The human immortalized keratinocytes cell line, HaCaT, (AddexBio, San Diego, CA, USA) was also used. Cells were cultured in Dulbecco's modified Eagle's medium supplemented with $4 \mathrm{mM}$ glutamine (DMEMg), $10 \%$ heat-inactivated fetal bovine serum (FBS), and $0.1 \mathrm{mg} / \mathrm{mL}$ of penicillin and streptomycin, in a humidified atmosphere containing 5\% $\mathrm{CO}_{2}$ at $37^{\circ} \mathrm{C}$, in $25 \mathrm{~cm}^{2}$ or $75 \mathrm{~cm}^{2}$ flasks.

\subsection{Antimicrobial activity}

For each bacterial strain, a fresh inoculum of microbial culture was allowed to grow at $37^{\circ} \mathrm{C}$ in Luria-Bertani (LB) medium until it reached an optical density of $0.8(\lambda=590 \mathrm{~nm})$. Then, microbial cultures were diluted in Mueller-Hinton (MH) broth at a concentration of $2 \times 10^{5}$ colony forming unit $(\mathrm{CFU}) / \mathrm{mL}$. Afterwards, aliquots $(50 \mu \mathrm{L})$ were added to $50 \mu \mathrm{L}$ of $\mathrm{MH}$ where all the selected compounds were properly diluted to reach the desired final concentration ranging from 64 to $16 \mu \mathrm{M}$. The plates were incubated at $37^{\circ} \mathrm{C}$ with gentle shaking and the microbial growth was evaluated after 16 hours by reading the samples absorbance (at $590 \mathrm{~nm}$ ) with a microplate reader (Infinite M200; Tecan, Salzburg, Austria). ${ }^{1}$ The percentage of microbial growth was calculated with respect to control samples (bacterial cells treated with vehicle, i.e. 2-methoxyethanol).

\subsection{Cytotoxicity assay}

The in vitro cytotoxicity of compounds 1, 2, 3 and 4 was evaluated by a colorimetric assay based on the reduction of the yellow dye MTT to its 
purple insoluble formazan by mitochondrial dehydrogenases. ${ }^{2}$ The intensity of the purple color is directly proportional to the percentage of metabolically-active cells. Briefly, 4 × $10^{4} \mathrm{HaCaT}$ cells were resuspended in DMEMg supplemented with $2 \%$ FBS and plated in each well of a 96well microtiter plate. After overnight incubation at $5 \% \mathrm{CO}_{2}$ and $37^{\circ} \mathrm{C}$, the medium was replaced by fresh serum-free DMEMg containing each compound at the desired concentration. For controls, keratinocytes were treated with vehicle (2-methoxyethanol). After incubation for $24 \mathrm{~h}$ at 37 ${ }^{\circ} \mathrm{C}$ and $5 \% \mathrm{CO}_{2}$, the medium of each well was replaced by Hank's buffer containing $0.5 \mathrm{mg} / \mathrm{mL}$ of MTT. The plate was incubated for additional $4 \mathrm{~h}$; afterwards, the formazan crystals were dissolved by adding acidified isopropanol to each well. ${ }^{3,4}$ The absorbance at $570 \mathrm{~nm}$ was measured by a microplate reader (Infinite M200; Tecan, Salzburg, Austria) and the percentage of metabolically-active cells was calculated with respect to the control (cells in medium supplemented with vehicle).

\subsection{Statistical analysis}

Statistical analysis was performed using Student's t-test and the differences were considered to be statistically significant for $p<0.05$.

\section{References}

1. Casciaro, B.; Lin, Q.; Afonin, S.; Loffredo, M. R.; de Turris, V.; Middel, V.; Ulrich, A. S.; Di, Y. P.; Mangoni, M. L., Inhibition of Pseudomonas aeruginosa biofilm formation and expression of virulence genes 
by selective epimerization in the peptide Esculentin-1a(1-21)NH2. The FEBS journal 2019, 286 (19), 3874-3891.

2. Grieco, P.; Carotenuto, A.; Auriemma, L.; Saviello, M. R.; Campiglia, P.; Gomez-Monterrey, I. M.; Marcellini, L.; Luca, V.; Barra, D.; Novellino, E.; Mangoni, M. L., The effect of d-amino acid substitution on the selectivity of temporin L towards target cells: identification of a potent anti-Candida peptide. Biochimica et biophysica acta 2013, 1828 (2), 652-60.

3. Cappiello, F.; Di Grazia, A.; Segev-Zarko, L. A.; Scali, S.; Ferrera, L.; Galietta, L.; Pini, A.; Shai, Y.; Di, Y. P.; Mangoni, M. L., Esculentin-1aDerived Peptides Promote Clearance of Pseudomonas aeruginosa Internalized in Bronchial Cells of Cystic Fibrosis Patients and Lung Cell Migration: Biochemical Properties and a Plausible Mode of Action. Antimicrobial agents and chemotherapy 2016, 60 (12), 7252-7262.

4. Di Grazia, A.; Cappiello, F.; Cohen, H.; Casciaro, B.; Luca, V.; Pini, A.; Di, Y. P.; Shai, Y.; Mangoni, M. L., D-Amino acids incorporation in the frog skin-derived peptide esculentin-1a(1-21)NH2 is beneficial for its multiple functions. Amino acids 2015, 47 (12), 2505-19. 